\title{
How approximate are the laws of plate tectonics?
}

Hallam (News and Views, 262, 94; 1976) has commented on a paper by Owen (Phil. Trans. R. Soc., A281, 223; 1976) who put forward a case for very substantial recent expansion of the Earth. Both writers discussing this problem (and certainly the history of $G$ is still a very open question, (Lewis, Nature, 261, 302; 1976) ) appear to base their arguments on what Hallam terms a fundamental tenet of plate tectonics, "that the amount of crust created at ocean ridges must equal the amount subducted elsewhere". This is in fact, a law of constancy of mass of both oceanic and continental crust. The purpose of this comment is to point out that such a basic tenet cannot hold exactly for a body like the Earth which is mixing as it cools. A major problem of our science today is to find out just how approximate such laws really are. It also seems that if continents are to fit like pieces of a puzzle, there must also be laws of constancy of area and shape. Again, this cannot be exact for we know that the processes which lead to separation change thickness.

While at present we certainly cannot exactly quantify major earth-shell interactions, certain facts must be considered and I would here draw attention to a few examples:

(1) The rate of delivery of potassium to the oceans by solution processes alone is about $7 \times 10^{13} \mathrm{~g} \mathrm{yr}^{-1}$. If such a value was typical throughout Earth history, then a mass of potassium equivalent to all that present in the continents would be delivered to the

\section{Reply}

Hallam replies: I am pleased that my News and Views article should have provoked Fyfe into writing his interesting letter giving geochemical reasons why the 'basic tenet' that crust created equals crust destroyed cannot be exactly true. It is indeed apparent that continental crustal thickness must change when separation takes place; the remarkable fact is that computerbased 'jigsaw fits' are for the most part so accurate to a first approximation. I feel no need to make further comments but Owen's letter calls for a brief reply.

My purpose was less to review Owen's paper than to use it as an excuse to discuss some awkward anomalies in continental fits which have not been adequately acknowledged or discussed by Earth scientists. I cited the Jansa and Wade, and Talwani and Eldholm, papers as examples of detailed recent work undermining oceans in about $5 \times 10^{9} \mathrm{yr}$. If we add the particulate contribution then the rate of removal of continents is much faster. As stated by Gilluly, Waters and Woodford (Principles of Geology, Freeman, 1975) "were the present rate of erosion for the United States maintained without further uplift or isostatic rebound, the country would be reduced to sea level in about 14 m.y."

(2) According to Sibley and Vogel (Science, 192, 551; 1976) "pelagic sediments, in contrast to other sediments, are not usually recycled; most are subducted and therefore act as a geochemical sink". Assuming some truth to this statement, then, as the rate of formation of pelagic sediments with about $3 \%$ potassium is about $1 \mathrm{~km}^{3} \mathrm{yr}^{-1}$, again this would subduct all continental potassium in $5 \times 10^{\circ} \mathrm{yr}$. The formation of such sediments involves the oceanic mixing process and a potassium atom from the Mississippi may well be subducted at the ChilePeru trench.

(3) Low $\mathrm{K}$ basalt comes up and higher $\mathrm{K}$ spilite is subducted (Keen, Geosci. Can., 2, 36; 1975). The surface layers of the ocean floor crust appear to average about $1 \%$ potassium. While there are many uncertainties (Fyfe, Geosci. Can., 3, 82; 1976) potassium removal by way of spilite subduction seems in the same order of magnitude as that supplied to the oceans by solution.

(4) Low quartz andesites debris (graywacke) may well be subducted at appropriate sites by way of the re- actions graywacke-glaucophane schistquartz-phlogopite eclogite. We know little of this process except that we do know that graywackes are dragged to depths of at least $30 \mathrm{~km}$ to form glaucophane schists.

In summary, there is good evidence that the continents cycle through the oceans and back to the mantle at a rate that could change crustal balance. In the spreading process, leading edges (the Andes for example) thicken and trailing edges must suffer massive erosion, even by solution. During the motions there need be no perfect conservation of mass or shape of continental crust.

Finally, it should be noted that the present configuration of the Earth would not be stable for a cooler, mixed, body. In such an Earth, the hydrosphere would hydrate the mantle, and "continental" elements like $\mathrm{K}$, Na, $\mathrm{SiO}_{2}$, would form stable compounds like phlogopite and pyroxene in the mantle. Our crust and hydrosphere, even if subducted (Fyfe, loc. cit.) tend to be thrown back by thermal processes.

But if the Earth is cooling, there must be increased mantle fixation of crustal components because the Earth is mixing. If we allow that the combined influences of all the above mentioned processes, subduct the continental mass about each billion years, then we could lose $20 \%$ in $200 \mathrm{Myr}$. Perhaps the interesting fact is that the steady-state approximation of plate tectonic theory is rather good.

W. S. FyfE the reliability of the geometric 500 fathom fit, with the implication that the same geological situation very probably holds for similar continental margins elsewhere in the world. The African margins are a good example, and absolutely crucial to reconstructions of Pangaea and to Owen's expanding Earth hypothesis. Yet Owen makes no allowance whatever for a broad zone of attenuated and subsided crust around this continent (see, for instance, his figure 11). The Burollet and Byramjee paper does not, admittedly, provide "definitive evidence", because it is in effect a broad-ranging review, and most of the critical data is based on unpublished work by oil companies. The paper does in fact contain substantial data for the region off Angola which cannot be lightly dismissed. Furthermore, Jansa and Wade spell out very clearly, with good evidence, that the north-west African continental margin is virtually a mirror image of that off eastern Canada and the United States. As for Madagascar, it is not very helpful to cite once again the much discussed paper by Flores. His purely geological arguments for a southerly position of that island can be countered by other geological arguments for a more northerly fit. The point is that the arguments based on geological comparisons with mainland Africa have proved indecisive, and that is why the palaeomagnetic results of McElhinny and Embleton are so important.

In conclusion, I repeat that $I$ find Owen's paper a stimulating one which deserves to be widely read, even though I am sceptical about his interpretation. If it serves to point up critical areas for further analysis it will have served a very useful purpose whatever one thinks of the conclusions.

A. Hallam 